\title{
REPENSANDO A IDEIA DE HELENIZAÇÃO: REVISITANDO O CASO DE 2 MACABEUS
}

\author{
Willibaldo Ruppenthal Neto \\ Universidade Federal do Paraná. Brasil
}

\begin{abstract}
Resumo: O presente artigo visa analisar o conceito historiográfico de "helenização" à luz do livro de 2 Macabeus e da realidade histórica do judaísmo helenístico. $\mathrm{O}$ tema central desta investigação, portanto, é a relação entre os judeus e a cultura grega no período helenístico, a fim de averiguar a validade do termo "helenização" para expressar a situação deste contexto histórico. O autor, após explicar o uso

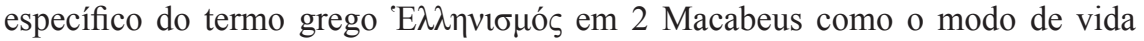

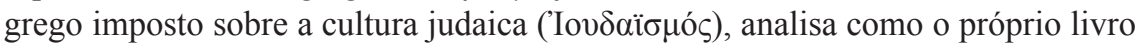
de 2 Macabeus e a realidade histórica contradizem a oposição que o autor de tal livro propõe aos termos.
\end{abstract}

Palavras-chave: Helenização - helenismo - judaísmo - mundo helenístico - 2 Macabeus - judeus - Asmoneus.

\section{REPENSANDO LA IDEIA DE HELENIZACIÓN: REVISANDO EL CASO DE 2 MACABEUS}

Resumen: El presente artículo busca analizar el concepto historiográfico de "helenización" a la luz del libro de 2 Macabeos y de la realidad histórica del judaísmo helenístico. El tema central de esta investigación, por lo tanto, es la relación entre los judíos y la cultura griega en el período helenístico, a fin de averiguar la validez del término "helenización" para expresar la situación de este contexto histórico. El autor, después de explicar el uso específico del término

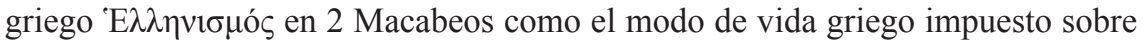

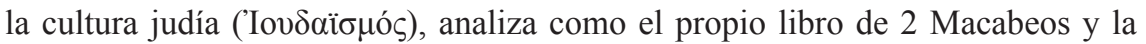
realidad histórica contradicen la oposición que el autor de tal libro propone a los términos.

Palabras clave: Helenización - helenismo - judaísmo - mundo helenístico - 2 Macabeos - judíos - Asmoneos. 


\title{
RETHINKING THE IDEA OF HELLENIZATION: REVISITING THE CASE OF 2 MACCABEES
}

\begin{abstract}
This article aims to analyze the historiographical concept of "Hellenization" in light of the book of 2 Maccabees and the historical reality of Hellenistic Judaism. The central theme of this investigation, therefore, is the relationship between the Jews and the Greek culture in the Hellenistic period, in order to ascertain the validity of the term "Hellenization" to express the situation of this historical context. The author, after explaining the specific use of the

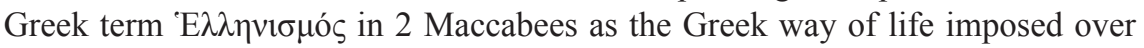

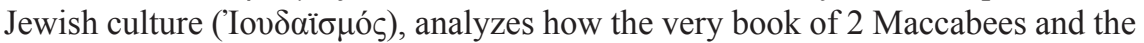
historical reality contradict the opposition that the author of such book proposes to the terms.
\end{abstract}

Keywords: Hellenization - Hellenism - Judaism - Hellenistic World - 2 Maccabees - Jews - Hasmoneans.

Recibido: 30.01.2019 - Aceptado: 31.01.2020

Correspondência: Willibaldo Ruppenthal Neto

E-mail: willibaldoneto@hotmail.com / professor.willibaldo@fabapar.com.br Bacharel e Licenciado em História pela Universidade Federal do Paraná (UFPR) Mestre em História pela UFPR. Doutorando em História pela UFPR. Membro discente do Núcleo de Estudos Mediterrânicos (NEMED) da UFPR. Professor das Faculdades Batista do Paraná (FABAPAR), Curitiba, Brasil. 


\section{Introdução ${ }^{1}$}

ecentemente, César Motta Rios (2017) apresentou um
excelente artigo a respeito do judaísmo helenístico,
demonstrando como é problemático se definir tal conceito, seja cronologicamente, seja pela relação com a cultura grega. De fato, a realidade histórica é muito mais fluida e complexa do que os termos historiográficos - tais como "judaísmo helenístico" - parecem indicar. Mesmo assim, como bem indicado por Rios, devemos reconhecer a necessidade que temos de tais expressões para definirmos elementos históricos.

O uso de conceitos historiográficos, porém, deve ser realizado com uma consciência crítica, não somente na reflexão a respeito da relação dos termos com a realidade histórica, mas também pelo conhecimento e averiguação das fontes, que servem como ferramentas de precisão para a calibração da balança conceitual de cada historiador. Sendo assim, uma das principais fontes judaicas do chamado "judaísmo helenístico", o livro de 2 Macabeus, pode servir como um importante meio de reflexão conceitual a fim de verificar a realidade histórica por trás e para além não somente da expressão "judaísmo helenístico", mas também do conceito de "helenização", ainda mais abrangente.

\section{1. "Helenização" em 2 Macabeus}

Apesar do conceito de "helenização" ter tido grande força e expressão na historiografia, especialmente com a ideia de "helenismo" propagada por Johann Gustav Droysen² e a própria expressão "helenização", utilizada por Arnaldo Momigliano ${ }^{3}$, trata-se de um conceito estabelecido sobre

1 Este artigo é parte (com modificações) de minha dissertação de mestrado em História pela UFPR intitulada "Judaísmo, uma invenção helenística: helenismo e judaísmo em 2 Macabeus", a qual defendida em 2018.

2 Segundo Droysen, Alexandre, o Grande, foi quem estabeleceu o "helenismo" quando, conquistando o território entre o deserto africano e a Índia, afirmou "a supremacia da civilização grega sobre a cultura declinante dos povos asiáticos" (Droysen, 2010, 37). Assim, para Droysen, o "helenismo" está construído não somente sobre a ideia de uma sobreposição cultural, mas também de uma superioridade. Sobre o "helenismo" em J. G. Droysen, cf. Biazotto, 2015; Caldas; Sant'Anna, 2008; Momigliano, 1970.

3 Sobre "helenização" em A. Momigliano, cf. Biazotto; Funari, 2015. 
uma exceção histórica. Afinal, mesmo que houvesse certa imposição de influência cultural por parte dos gregos sobre os orientais no período

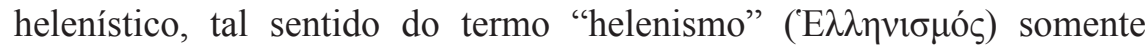
aparece em um trabalho que, segundo o próprio Momigliano, é "algo único na historiografia antiga" (Momigliano, 1975b, 81): o livro de 2 Macabeus.

Diferente da grande maioria dos casos da Antiguidade, nos quais o termo E E $\lambda \eta \eta \nu \imath \sigma \mu o ́ \varsigma$ é utilizado ou como o uso correto da língua grega ${ }^{4}$, ou como o grego do mundo helenístico, denominado кoเv $\eta^{5}$, em 2 Macabeus ele aparece como expressão do modo de vida grego (Himmelfarb, 1998, 24), o qual é imposto sobre os judeus, os quais são defendidos por aqueles que,

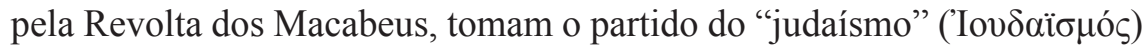
- termo que aparece neste contexto pela primeira vez na história ${ }^{6}$. Assim,

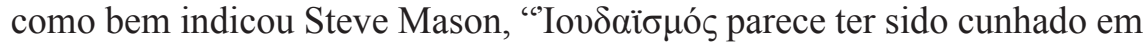
reação ao 'E $\lambda \lambda \eta v i \sigma \mu o ́ \varsigma \varsigma$ cultural, que o autor [de 2 Macabeus] também deve ter sido o primeiro a usar em sentido de "helenização"' (Mason, 2007, 464). Mas, será que deve-se falar em "helenização" ou "helenismo", como uma força impositiva da cultura grega sobre as demais no período helenístico? Será que o livro de 2 Macabeus acompanha a realidade histórica em

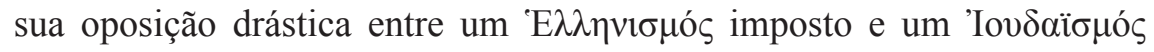
resistente?

$4 \quad$ Este sentido do termo foi empregado por Diógenes da Babilônia (3.214), por Filodemo (Peri poiematon, 2.18), por Apolônio Díscolo (de Pronominibus, 71.25), por Sextus Empiricus (adversus Mathematicos, 1.98), e também aparece no Léxico Vindobonense. É o sentido mais próximo do verbo grego E E $\lambda \lambda \eta v i ́ \xi \omega$, com sentido de falar o grego corretamente. Cf. Liddell; Scott; Jones, 1996, 536.

5 Cf. Oxyrhynchus Papyri 1012 (Toledo Museum of Art, Ohio, USA), frag.

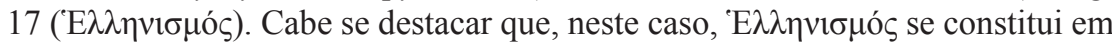

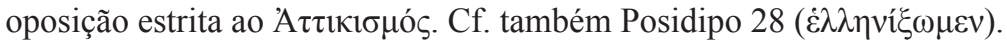

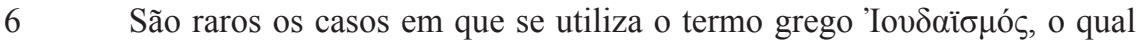
inclusive não possui nem mesmo um termo equivalente no hebraico (Mason, 2007, 460). Os casos mais antigos do uso deste termo são: três passagens de 2

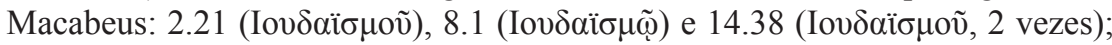

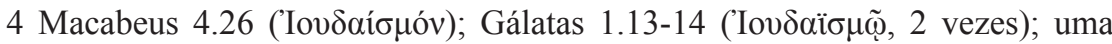

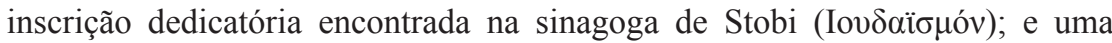

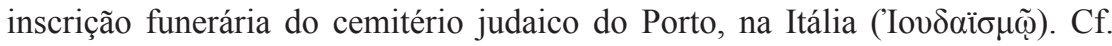
Amir, 1982, 35-36. 
Mesmo que 2 Macabeus passe uma ideia do helenismo (E $\lambda \lambda \eta \nu \imath \sigma \mu o ́ \varsigma)$ como imposição, se pode perceber, dentro do próprio relato, a existência de uma efetiva participação judaica na entrada do ${ }^{\circledR} \mathrm{\lambda} \lambda \lambda \eta \nu \imath \sigma \mu$ ó $_{\zeta}$ na Judeia ${ }^{7}$, ou seja, se deve considerar a possibilidade não somente de "judeus helenizados" mas também de "judeus helenizantes". Neste sentido, "helenização" também poderia ser compreendida como "um movimento político" que, como bem define Uriel Rappaport, "se esforçou para alcançar certos objetivos", não somente suplantando o sumo sacerdócio de Onias III - seja com Jasão ou com Menelau ${ }^{10}$ - mas também estabelecendo Jerusalém como uma cidade grega (Rappaport, 1992, 1).

Deste modo, mesmo que os judeus helenizantes fossem diferenciados pela adoção de costumes gregos, pode bem ser que seus objetivos fossem "primariamente políticos do que culturais" (Rappaport, 1992, 1), mirando não contra a tradição judaica, mas contra o poder dos Oníadas ${ }^{11}$. A

7 Se em 2 Macabeus Jasão pede autorização real para construção do Ginásio, em 1 Macabeus "uma geração de perversos" (1 Mac 1.11) pede autorização para Antíoco a fim de "observarem os costumes pagãos" (1 Mac 1.13). Em ambos os casos, portanto, a iniciativa é judaica, e não selêucida. Se em 2 Macabeus esta iniciativa parece ser um ato isolado de Jasão, em 1 Macabeus fica clara a existência de um grupo de judeus helenizantes.

8 Como destacou Vasile Babota, tornar-se "helenizado" não "resulta necessariamente em perda (completa) de uma identidade étnica ou religião" (Babota, 2014, p. 48).

9 A compreensão da existência de um grupo de "judeus helenizantes" prevalece na historiografia desde a publicação de Elias J. Bickerman de sua obra Der Gott der Makkabäer, em 1937. Cf. Bickerman, 2007 (Volume II).

10 Segundo Jonathan A. Goldstein (1983, 85), haveria uma diferenciação entre os judeus helenizantes apoiadores de Jasão e aqueles que apoiaram Menelau.

11 André Chevitarese lembra que os "choques" do período macabeu se deram no conflito resultante da divisão da sociedade judaica entre facções "entre famílias dominantes e poderosas judaicas", a exemplo dos Tobíadas, Oníadas, Simônides e Asmoneus, "que buscavam alcançar liderança e autoridade sobre a comunidade", uma vez que "atingir estes dois objetivos, por parte dessas famílias, significava controlar o tesouro do Templo, a coleta de impostos, além de garantir privilégios e ganhos palpáveis da sociedade tanto interna quanto externamente" (Chevitarese, 2004, 77). 
"helenização", portanto, mais do que um objetivo religioso ou cultural, poderia ser antes uma consequência de suas posições e ações políticas ${ }^{12}$.

\section{Os judeus e a cultura helenística}

A relação entre os judeus e a cultura helenística, portanto, não é algo simples. Esta relação foi marcada por diversas atitudes, de modo que "muito da história da civilização judaica no mundo Greco-Romano pode ser visto como uma luta para definir como exatamente os judeus deveriam se relacionar com esta cultura estrangeira" (Bohak, 2000, 351). Entre a completa negação e a absoluta adesão à cultura grega, há uma gama de possibilidades e formas de interações que não somente marcaram a grande maioria do povo judeu, mas também pode ter sido o espaço dentro do qual os indivíduos pertencentes àqueles grupos aparentemente opostos estiveram. Talvez as intenções que dividiam as poderosas famílias judaicas (dos Oníadas, Tobíadas, Simônides e Asmoneus) fossem mais econômicas e políticas que de fato culturais, apesar do que foi transmitido pelos relatos do contexto, a exemplo de 2 Macabeus.

Também, a usual tendência da grande maioria dos povos orientais de não negar completamente nem aderir completamente aos modos de vida gregos $^{13}$ parece contrariar a proposta de uma polarização distante

12 Victor Tcherikover argumenta que a reforma dos judeus helenizantes foi motivada por razões primariamente políticas e econômicas, de modo que "as mudanças na esfera da religião e cultura não foram a razão da reforma, mas suas consequências" (Tcherikover, 1959, 169). Neste sentido, a crítica de Tessa Rajak à identificação deste grupo judaico que se opôs aos Macabeus como "helenizantes" (Rajak, 2001, 7) é relevante, uma vez que é bem provável que a "crise cultural" do período macabeu tenha sido causada por "querelas políticas, a saber, relacionamentos conflitantes com o poder dominante" (Rajak, 2001, 2). Pode-se pensar nestes relacionamentos como posicionamentos pró-selêucidas ou pró-ptolomaicos das facções judaicas, cf. Chevitarese, 2004, 77. Para diferentes interpretações, cf. Santana, 2013, 43.

13 Como lembra Lester Grabbe, a Fenícia é "um exemplo útil em como a helenização pode penetrar na cultura sem substituir a cultura nativa" (Grabbe, 2002, 61), uma vez que, apesar das cidades fenícias terem se tornado $\pi$ ó $\ell \varepsilon 1 \zeta$ gregas, a "cultura fenícia continuou em todos os níveis, tanto na Fenícia como nas colônias marítimas" (Grabbe, 2002, 61). Para Fergus Millar, "as cidades fenícias são os exemplos mais claros de cidades pré-gregas que mantiveram suas tradições e identidades enquanto também se tornaram integradas no mundo 
entre os grupos judaicos do contexto macabeu ${ }^{14}$ que 2 Macabeus apresenta. Afinal, se havia uma imposição da cultura grega sobre a cultura judaica, qual a razão do mesmo não ter ocorrido em outros contextos e com outras culturas? É mais provável que tal "imposição" tenha sido muito mais uma fusão cultural que, aos olhos de determinados grupos judaicos, foram vistos como imposição, ou ainda foram assim definidos a fim de se defender a própria revolta cuja "bandeira" era a defesa do judaísmo frente ao helenismo imposto. Afinal, a completa oposição entre judaísmo e helenismo é refutada pelo próprio livro de 2 Macabeus que, além de ter sido escrito em grego ${ }^{15}$, carrega dentro de si aspectos próprios da cultura grega, que afetam não somente a forma do livro, mas também indicam uma intencionalidade, influenciando seu método e estilo, por exemplo, de modo que "a forma literária grega de 2 Macabeus representa mais que uma influência grega superficial" (Himmelfarb, 1998, 20). Assim, considerando a influência grega e a ideologia transmitida pela própria obra, 2 Macabeus se configura em uma contradição: "é ao mesmo tempo judaica em sua piedade, e grega em seu modo de expressão" (Himmelfarb, 1998, 20).

A ideia de uma oposição absoluta entre dois grupos opostos - um "helenizante" e outro "tradicionalista" - também é refutada pela própria realidade histórica. Mesmo que se possa pensar, a partir da leitura de 2 Macabeus, que a Revolta dos Macabeus teve como propósito principal a

helenístico e romano" (Millar, 2006a, 71), de modo que se tem como evidência o fato das inscrições em fenício continuarem até o tempo de Augusto e o uso das letras fenícias em moedas em Tiro até o final do séc. II d.C. Também, na Fenícia helenística houve tanto uma continuidade de cultos, mesmo com assimilações de aspectos gregos (cf. Eusébio, Praeparatio Evangelica, 1.10.55), ao mesmo tempo que a preservação de uma tradição literária (Millar, 2006a, 72), da qual Filo de Biblos é um exemplo. Sobre o caso fenício, cf. Millar, 2006b, 32-50.

14 Segundo Martin Hengel todo o judaísmo a partir do séc. III a.C., em suas diversas expressões, deveria ser designado como “'judaísmo helenístico' em senso estrito" (Hengel, 1974, 106 [I]).

15 Diferente de 1 Macabeus, que foi escrito originalmente em hebraico e depois traduzido para o grego, o livro de 2 Macabeus é evidentemente um texto composto em língua grega. Não acompanha, portanto, a tendência de alguns judeus em se evitar o uso da língua grega ou mesmo o uso de termos gregos, valendo-se não somente da língua, mas também de conceitos próprios da cultura grega, apesar de estabelecer profundas e importantes ressignificações, como no

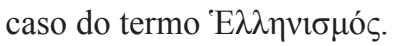


eliminação do 'E $\lambda \lambda \eta v i \sigma \mu o ́ \varsigma$ da Judeia e da cultura judaica, a Revolta dos Macabeus, tal como as demais revoltas orientais, não buscou separar completamente a cultura nativa do 'E $\lambda \lambda \eta v \imath \sigma \mu$ óc. Afinal, "apesar das revoltas orientais se constituírem numa reação nacional contra a casa Selêucida, elas estavam longe de implicar em um completo divórcio das formas políticas e aspectos culturais do helenismo" (Coyne, 1912, 600), e o caso judaico não foi exceção: a dinastia dos Asmoneus, que subiu ao poder com a Revolta, não apenas foi marcada por fortes influências gregas ${ }^{16}$, mas também parece ter surgido sem uma verdadeira pretensão de distanciamento da cultura helênica ${ }^{17}$.

\section{Os Asmoneus e a cultura helenística}

Os Asmoneus não foram marcados somente pelo amplo uso de nomes $\operatorname{gregos}^{18}$, mas também por um uso mais profundo do próprio ${ }^{\circledR} \lambda \lambda \eta v i \sigma \mu o ́ s$

16 "Até ganhando independência do domínio grego não significava necessariamente na derrubada da cultura helenística ou a eliminação de todos elementos e influências gregos, como ficou claro pelo exemplo dos Asmoneus" (Grabbe, 2002, 62).

17 Como indica Timo Nisula, "já em suas origens, a corte Asmoneia não era - e talvez nem quisesse ser - imune às influências gregas" (Nisula, 2005, 219). Segundo Uriel Rappaport, os nomes gregos dos emissários de Judas, Eupolemo e Jasão, são um indicativo. Cf. Rappaport, 1992, 10, nota 5. Com o decorrer do tempo, há inclusive uma aproximação da cultura grega, como se atesta pelo título $\Phi \mathbf{1} \lambda \hat{\varepsilon} \lambda \lambda \eta v$, "amigo dos gregos", dado a Judas Aristóbulo I. Cf. Josefo, Antiquitates Judaicae, 13.318-319. Este título, porém, não deve causar más interpretações: os Asmoneus, apesar de terem aspectos da cultura grega, eram acusados de destruírem cidades gregas. Cf. Efron, 1987, 166-167, nota $106 ; 235-236$, nota 61 .

18 Tal Ilan, analisando os nomes hebraicos e gregos dos reis Asmoneus, destacou o fato de que os nomes hebraicos eram reproduzidos em grande quantidade pela população, enquanto os nomes gregos dos Asmoneus raramente eram usados, concluindo a partir disto que a "tendência à helenização da parte dos asmoneus era muito impopular entre o povo, como a distribuição de seus nomes gregos mostra" (Ilan, 1987, 15). Seu estudo foi feito a partir de 2000 nomes de judeus do período. Segue a lista dos nomes duplos dos monarcas Asmoneus: João Hircano, Judas Aristóbulo, Jônatas Alexandre, Matatias Antígono, Jônatas Aristóbulo. Também são atestados outros reis possuindo alguns destes nomes gregos (Hircano, Aristóbulo, Alexandre, Antígono), sem que saibamos seus 
em sua política ${ }^{19}$, ao ponto de Arnaldo Momigliano (1975a, 114) poder afirmar que "em termos de organização política e econômica, os judeus estavam certamente mais helenizados depois da Revolta dos Macabeus do que antes" 20 . Tal "helenização" pode ter chegado inclusive ao ponto de João Hircano e suas tropas se juntarem a Antíoco VII em uma campanha contra os partos, conforme o relato de Josefo ${ }^{21}$, já em 131-129 a.C.22.

Seja como for, a cunhagem de moedas dos Asmoneus ${ }^{23}$ reflete uma influência helênica e selêucida, não somente nas imagens representadas - como a rosa, o lírio, a cornucópia, a grinalda, a [folha de] palma, o diadema, a estrela e a âncora ${ }^{24}$ (cf. a tabela 1 abaixo) -, mas também com o

nomes hebraicos. Cf. Ilan, 1987, 18.

19 No que diz respeito ao aspecto helênico do governo Asmoneu, pode-se inclusive ser apontado seu caráter tirânico: afinal, como lembra Eric M. Meyers, "os descendentes de Judas Macabeu [i.e., os Asmoneus] estabeleceram uma dinastia e um reino tirânicos que era mais parecido com aquelas dos tiranos helenísticos do que dos antigos governantes de Israel" (Meyers, 1992, 85). Também a própria corte asmoneia, de certa forma, era ao estilo grego, cf. Regev, 2013. Cf. Josefo, $A J, 13.302,415-416$. Sobre o helenismo dos Asmoneus, cf. Rappaport, 1992, 1-13; Rajak, 2001, 61-80. Arnaldo Momigliano indica ainda como característica helenística a formação do exército Asmoneu por mercenários. Cf. Momigliano, 1988, 249.

20 Como indicou Lester Grabbe, ao contrário do esperado, a Judeia sob o domínio dos Asmoneus foi tipicamente semelhante aos "reinos helenísticos daquele período em geral" (Grabbe, 2002, 62).

Josefo, $A J, 13.250-251$.

22 Cf. Dabrowa, 2009, 69. Deve-se admitir, porém, que este relato de Josefo, baseado em Nicolau de Damasco, é o único que menciona a participação de João Hircano. Cf. Dabrowa, 2009, 69.

23 Segundo o relato de 1 Macabeus (15.6), o direito de cunhar moedas foi concedido por Antíoco VII Sidetes (138-129 a.C.) ao sumo-sacerdote Simão (142-135 a.C.). Cf. Lykke, 2012, 89ss.

24 Segundo Lykke, tanto a rosa como o lírio eram bastante utilizados na iconografia grega. No caso da rosa, pode ter havido influência da cunhagem de moedas da ilha de Rodes, similares às representações judaicas. Cf. Lykke, 2012, 97. As cornucópias, além de representarem a prosperidade e abundância, são utilizadas na cunhagem ptolomaica a partir de Ptolomeu II. Deste modo, muitas das representações judaicas encontram paralelos não somente na cunhagem 
uso, mesmo que esporádico, de monogramas e letras gregos ${ }^{25}$.

\begin{tabular}{|c|c|}
\hline Monarca Asmoneu & Imagens cunhadas \\
\hline João Hircano I (135-104 a.C.) & $\begin{array}{c}\text { Cornucópia (dupla com romã e } \\
\text { paralela), grinalda, rosa, elmo, rosa, } \\
\text { palma }\end{array}$ \\
\hline Judas Aristóbulo I (104-103 a.C.) & $\begin{array}{c}\text { Cornucópia (dupla com romã), } \\
\text { grinalda }\end{array}$ \\
\hline Alexandre Janneu (103-76 a.C.) & $\begin{array}{c}\text { Cornucópia (dupla com romã), } \\
\text { grinalda, rosa, palma, lírio, âncora, } \\
\text { diadema, estrela }\end{array}$ \\
\hline Judas Aristóbulo II (67-63 a.C.) & $\begin{array}{c}\text { Cornucópia (dupla com romã), } \\
\text { grinalda }\end{array}$ \\
\hline João Hircano II (63-40 a.C.) & $\begin{array}{c}\text { Cornucópia (dupla com romã), } \\
\text { grinalda }\end{array}$ \\
\hline Matatias Antígono (40-37 a.C.) & $\begin{array}{c}\text { Cornucópia (única, dupla, com romã } \\
\text { e com grãos), grinalda, menorá, mesa } \\
\text { de pão }\end{array}$ \\
\hline
\end{tabular}

Tabela 1 - Imagens utilizadas nas moedas dos Asmoneus ${ }^{26}$

selêucida (cf. Lykke, 2012, 100; Kindler, 2000, 317-322), mas também de outras partes do mundo helenístico. Sobre a influência helenística nas cunhagens judaicas, cf. esp. Kindler, 2000. Sobre o uso de âncoras em cunhagens judaicas, cf. Jacobson, 2000.

25 Normalmente moedas de João Hircano II (63-40 a.C.). Cf. Kanael, 1952; Kindler, 1952.

26 Fonte: Lykke, 2012, 96 (Text Table II). 
Dentre todas as cunhagens dos Asmoneus, certamente a mais claramente influenciada por elementos da cultura helênica foi a estabelecida sob o reinado de Alexandre Janneu ${ }^{27}$, marcada não somente pela retomada do uso da âncora invertida (comum na cunhagem selêucida ${ }^{28}$ e também na cunhagem de João Hircano ${ }^{29}$, sendo depois somente retomada por Janneu), mas também por inscrições em grego, a exemplo de uma moeda de bronze de Alexandre Janneu, moeda com uma estrela de oito pontas e uma inscrição em hebraico ("o rei Yehonatan") de um lado, e uma âncora invertida ao centro com inscrição em grego (BA $\Sigma \Lambda \Lambda E \Omega \Sigma A \Lambda E \Xi A N \Delta P O Y)$ do outro $^{30}$. Tais cunhagens expressam uma política fortemente influenciada por aspectos da cultura grega, marca principal do reinado de Alexandre Janneu.

Levando em consideração que nenhum rei governa sem apoio da sociedade, seja das massas populares ou da elite social, pode-se dizer que é bem provável que suas ações de "helenização" não somente tenham contado com apoio de um número considerável de judeus, mas talvez até

27 Se a "mais copiosa e variada" cunhagem de moedas se deu sob Alexandre Janneu, outra importante cunhagem se deu sob Matias Antígono. Há, porém, uma grande diferença entre as duas variações: se no caso de Janneu há uma grande variedade de influências (Rappaport, 1984, 38), no caso de Matias há uma evidente busca de fortalecimento da identidade judaica mediante a cunhagem de moedas utilizando-se de novos símbolos tomados da tradição judaica, a exemplo da menorá e da mesa de pães. Mesmo assim, Matias também apresenta o uso de inscrições gregas em suas moedas, tal como Janneu, sendo que somente os dois utilizaram tal meio entre todos os reis Asmoneus. Cf. Lykke, 2012, 105.

Cf. Dabrowa, 2009, 69, nota 10.

29 Pode-se afirmar que houve um verdadeiro padrão de cunhagem com a representação de uma âncora no anverso e um lírio no reverso, formando um padrão "âncora-lírio" (inglês: anchor-lily). Segundo Anne Lykke, as moedas de João Hircano I cunhadas com a âncora e o lírio funcionaram como uma moeda transicional, marcando o começo da cunhagem dos Asmoneus. Cf. Lykke, 2012, 89; Hendin, 2010, 181. No caso de Alexandre Janneu, porém, fica evidente a busca por retomar um padrão helenístico selêucida, bastante característico de seu reinado em ainda outros aspectos como a própria política interna (perseguindo os fariseus, p.e.).

30 Cf. Hendin, 2010, 1150. Cunhagem de Jerusalém, 2.246 g., 15.9 mm., 95-76 a.C. 
mesmo fossem realizadas visando tal aprovação - o que supõe a existência de judeus que, se não eram defensores da incorporação da cultura grega como um todo, eram pelo menos adeptos da incorporação de elementos específicos, a exemplo da língua grega, justificando o fato de que no século primeiro o grego já estava presente, na Palestina, "no comércio e nos negócios, mesmo pelos menos educados, num grau muito maior do que os estudiosos têm assumido" (Jaeger, 2002, 18, nota 7) ${ }^{31}$.

Sendo assim, se de fato antes da Revolta dos Macabeus houve uma luta cultural "pelas mentes e corações" dos judeus, como definiu Ranon Katzoff $(1985,489)$, pode-se pensar que mesmo após a vitória dos Macabeus o grupo dos judeus helenizados "permaneceu como um fenômeno cultural e o próprio processo de organização política serviu como um fator importante na sua difusão", como indicou Victor Tcherikover (1959, 249-250). Afinal, em boa medida o evergetismo ${ }^{32}$, característico do mundo helenístico (marcando forte presença no contexto romano ${ }^{33}$ ),

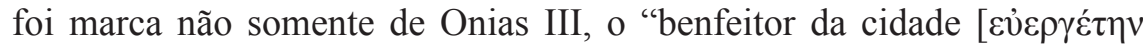
$\tau \tilde{\eta} \varsigma \pi$ ó $\lambda \varepsilon \omega \varsigma$ ]" (2 Mac 4.2), mas também dos Asmoneus ${ }^{34}$, o que indica a presença de judeus helenizantes mesmo depois da Revolta, apoiando estas medidas e tornando-as possíveis.

31 Pesquisas recentes têm confirmado a tese de Jaeger. O estudo de Hans Debel, por exemplo, mostra que "a presença de inscrições gregas, nomes e palavras emprestadas em hebraico e aramaico a partir do séc. II d.C. adiante, assim como os fragmentos gregos descobertos em Qumran, tudo demonstra que o grego era aprendido, entendido e ativamente usado na Palestina por volta da virada da Era" (Debel, 2010, 182). Sobre o uso da língua grega pelos judeus, cf. Baumgarten, 2002, 13-30; Mussies, 1976, 1040-1064.

32 "Evergetismo" é um neologismo criado para expressar a ação de alguém

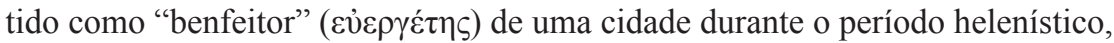
o qual contribuía com a cidade através de comida, construções, jogos, campanhas militares, etc, em troca de reconhecimento e recompensas com alto

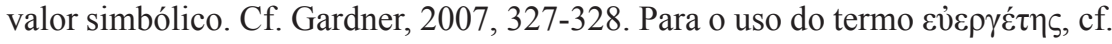
Liddell; Scott; Jones, 1996, 712; normalmente possuía o sentido de benfeitor, cf. Heródoto, Historiae, 6.30; Eurípides, Hercules Furens, 1252; Rhesus, 151; Platão, Cratylus, 403e.

Cf. Veyne, 2015.

34 Cf. 1 Mac 14.25-49 (Simão); Josefo, $A J$, 14.149-155 (João Hircano I); Josefo, AJ, 13.318 (Aristóbulo I); Rajak, 2001, p. 373-391; Gardner, 2007. 


\section{Considerações finais}

O estudo aprofundado da relação entre a cultura helenística e os judeus no período helenístico e no livro de 2 Macabeus deixam claro que a realidade histórica foi muito mais fluida e complexa do que o autor de 2 Macabeus indicou. Ao mesmo tempo, apesar de ser historicamente problemático, o termo "helenização", assumido como uma interpretação e sentido específicos do termo grego 'E $\lambda \lambda \eta \nu 1 \sigma \mu o ́ s$, pode ser repensado a fim expressar mais fielmente a realidade histórica ao invés da imagem que costuma carregar. Por fim, tal estudo permite também que se perceba que o helenismo, ou helenização, compreendido como a troca cultural dentro do mundo greco-romano serviu não somente para o encontro com o "outro" 35 , mas também na construção de identidades do próprio "eu" coletivo, decorrente deste contato, seja pela aproximação ou ainda pela oposição.

\section{REFERÊNCIAS BIBLIOGRÁFICAS:}

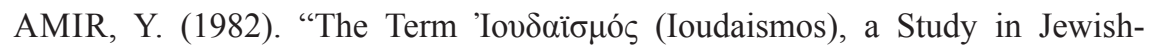
Hellenistic Self-Identification", Immanuel, 14, 34-41.

BABOTA, V. (2014). The Institution of the Hasmonean High Priesthood. Leiden/ Boston: Brill. (Supp JSJ, 165).

BAUMGARTEN. A. I. (2002). "Bilingual Jews and the Greek Bible", In: Kugel, James L. (Ed.). Shem in the Tents of Japhet: Essays on the Encounter of Judaism and Hellenism. Leiden/Boston/Köln: Brill. (Supp JSJ, 74), 1330 .

BIAZOTTO, T. DO A. (2015). "O helenismo de Johann Gustav Droysen: conceito, contexto e crítica", Revista Mundo Antigo, IV, 4(7), 181-190.

BIAZOTTO, T. DO A.; FUNARI, P. P. A. (2015). "A sabedoria bárbara e os limites da helenização: o mundo helenístico de Arnaldo Momigliano", História da Historiografia, 17, 244-261.

BICKERMAN, E. J. (2007). Studies in Jewish and Christian History. A New Edition in English including The God of the Maccabees. Introduced by Martin Hengel. Edited by Amram Tropper. Leiden/Boston: Brill. (Ancient Judaism and Early Christianity, 68). Volume II.

BOHAK, G. (2000). "Hellenism", In: Lawrence H. Schiffman \& James C. VanderKam (Ed.). Encyclopedia of the Dead Sea Scrolls. Oxford: Oxford University Press, 350-352 (I).

$35 \quad$ Conforme bem indicado por César García Álvarez (2018) em um artigo recentemente publicado na revista Byzantion Nea Hellás. 
CALDAS, P. S. P.; SANT'ANNA, H. M. DE. (2008). “'Fixar a onda de luz': O problema da transição das épocas históricas no conceito de helenismo em Johann Gustav Droysen", História da Historiografia, 1, 88-101.

CHEVITARESE, A. L. (2004). "Fronteiras culturais no Meditarrâneo Antigo: gregos e judeus nos períodos Arcaico, Clássico e Helenístico", Politeia: História e Sociedade, 4(1), 69-82.

COYNE, J. J. A. (1912). "Hellenism and the Oriental Reaction”, Studies: An Irish Quarterly Review, 1(4), 599-620.

DABROWA, E. (2009). The Hasmoneans and their State: A Study in History, Ideology, and the Institutions. Kraków: Jagiellonian University Press. (Electrum: Studies in Ancient History, 16).

DEBEL, H. (2010). "Greek 'Variant Literary Editions' to the Hebrew Bible?", Journal for the Study of Judaism, 41, 161-190.

DROYSEN, J. G. (2010). Alexandre o Grande. Rio de Janeiro: Contraponto.

EFRON, J. (1987). Studies on the Hasmonean Period. Leiden; København; Köln; New York: Brill. (Studies in Judaism in late antiquity, 39).

GARCÍA ÁLVAREZ, C. (2018). "El helenismo o la búsqueda del "otro", Byzantion Nea Hellás, 37, 121-141.

GARDNER, G. (2007). "Jewish Leadership and Hellenistic Civic Benefaction in the Second Century B.C.E", Journal of Biblical Literature, 126(2), 327343.

GOLDSTEIN, J. A. (1983). II Maccabees: A New Translation with Introduction and Commentary by Jonathan A. Goldstein. New York: Doubleday. (The Anchor Bible).

GRABBE, L. L. (2002). "The Jews and Hellenization: Hengel and his critics", In: Davies, Philip R.; Halligan, John M. (Ed.). Second Temple Studies III: Studies in Politics, Class and Material Culture. Sheffield: Sheffield Academic Press. (Journal for the Study of the Old Testament Supplement Series, 340), 52-66.

HENDIN, D. (2010). Guide to Biblical Coins. 5th Edition. New York: Amphora. HENGEL, M. (1974). Judaism and Hellenism: Studies in their Encounter in Palestine during the Early Hellenistic Period. 2 Volumes. Philadelphia: Fortress Press.

HIMMELFARB, M. (1998). "Judaism and Hellenism in 2 Maccabees", Poetics Today, 19(1), 19-40.

ILAN, T. (1987). "The Greek Name of the Hasmoneans", Jewish Quarterly Review, New Series, 78(1/2), 1-20.

JACOBSON, D. M. (2000). "The Anchor on the Coins of Judaea", Bulletin of the Anglo-Israel Archaeological Society, 18, 73-81.

JAEGER, W. (2002). Cristianismo Primitivo e Paideia Grega. Lisboa: Edições 70. (Colecção Perfil: História das Ideias e do Pensamento, 6). 
KANAEL, B. (1952). The Greek Letters and Monograms on the Coins of Jehohanan the High Priest. Israel Exploration Journal, 2(3), 190-194.

KATZOFF, R. (1985). "Jonathan and Late Sparta”, American Journal of Philology, 106(4), 485-489.

KINDLER, A. (1952). "Rare and Unpublished Hasmonean Coins", Israel Exploration Journal, 2(3) 188-189.

--- "The Hellenistic Influence on the Hasmonean Coins", In: Kluge, Bernd; Weisser, Bernhard. (Ed.). XII Internationaler Numismatischer Kongress. Berlin 1997. Akten - Proceedings - Actes I. Berlin: Staatliche Museen zu Berlin; B. G. Mann Verlag, 316-323.

LIDDELL, H. G.; SCOTT, R.; JONES, H. S. (1996). A Greek-English Lexicon. Compiled by Henry George Liddell and Robert Scott. Revised and Augmented throughout by Sir Henry Stuart Jones with the Assistance of Roderick McKenzie and with the cooperation of many scholars. With a revised Supplement. Oxford: Clarendon Press.

LYKKE, A. (2012). Reign and Religion in Palestine: The Political Instrumentalization of Sacred Iconography in the Hellenistic-Roman Period on the Basis of the Numismatic Evidence. 480 f. Dissertation (Klassische Archäologie) - Universität Wien, Wien.

MASON, S. (2007). "Jews, Judaeans, Judaizing, Judaism: Problems of Categorization in Ancient History", Journal for the Study of Judaism, 38, 457-512.

MEYERS, E. M. (1992). "The Challenge of Hellenism for Early Judaism and Christianity", Biblical Archaeologist, 55(2), 84-91.

MILLAR, F. (2006a). "The Background to the Maccabean Revolution: Reflections on Martin Hengel's 'Judaism and Hellenism'”, In: Millar, Fergus. Rome, the Greek World, and the East. Volume 3: The Greek World, the Jews, and the East. Edited by Hannah M. Cotton and Guy M. Rogers. Chapel Hill: The University of North Carolina Press, 67-90.

--- (2006b). "The Phoenician Cities: A Case-Study of Hellenisation", In: Millar, Fergus. Rome, the Greek World, and the East. Volume 3: The Greek World, the Jews, and the East. Edited by Hannah M. Cotton and Guy M. Rogers. Chapel Hill: The University of North Carolina Press, 3250.

MOMiglianO, A. (1975a). Alien Wisdom: The Limits of Hellenization. Cambridge: Cambridge University Press.

--- (1988). "Ioudaïsmos-hellénismos: Essai sur le judaïsme judéen à l'époque hellénistique by Édouard Will; Claude Orrieux" (Review), Classical Philology, 83(3), 248-251.

--- (1970). "J. G. Droysen between Greeks and Jews", History and Theory, 9(2), 139-153. 
--- (1975b). "The Second Book of the Maccabees", Classical Philology, 70(2), 81-88.

MUSSIES, G. (1976). "Greek in Palestine and the Diaspora", In: Safrai, Shmuel. et al. (Ed.). The Jewish People in the First Century: Historical Geography, Political History, Social, Cultural and Religious Life and Institutions. Volume 1. Assen: Van Gorcum. (CRINT), 1040-1064.

NISULA, T. (2005). “Time has passed since you sent your letter': Letter Phraseology in 1 and 2 Maccabees", Journal for the Study of the Pseudepigrapha, 14(3), 201-222.

RAJAK, T. (2001). The Jewish Dialogue with Greece and Rome: Studies in Cultural and Social Interaction. Leiden/Boston/Köln: Brill. (Arbeiten zur Geschichte des Antiken Judentums und des Urchristentums, 48).

RAPPAPORT, U. (1984). "Numismatics", In: W. D. Davies \& Louis Finkelstein (Ed.). The Cambridge History of Judaism. Cambridge: Cambridge University Press. Volume 1: Introduction; The Persian Period, 25-59.

--- (1992). "The Hellenization of the Hasmoneans", In: Mor, Menahem. (Ed.). Jewish Assimilation, Acculturation and Accomodation: Past Traditions, Current Issues and Future Prospects. Proceedings of the Second Annual Symposium of the Philip M. and Ethel Klutznick Chair in Jewish Civilization held on Sunday-Monday, September 24-25 1989. Lanham/New York/London: Creighton University. (Studies in Jewish Civilization, 2), 1-13.

REGEV, E. (2013). The Hasmoneans: Ideology, Archaeology, Identity. Göttingen/ Bristol: Vandenhoeck \& Ruprecht.

RIOS, C. M. (2017). “O que é e não é judaísmo helenístico?”, Caminhos, 15(2), 234-248.

SANTANA, T. B. DE. (2013). "O modus vivendi helênico e a Revolta dos Macabeus no séc. II a.C", Oracula, 9(14), 31-45.

TCHERIKOVER, V. (1959). Hellenistic Civilization and the Jews. Philadelphia/ Jerusalem: The Jewish Publication Society of America/The Magness Press, The Hebrew University.

VEYNE, P. (2015). Pão e circo: sociologia histórica de um pluralismo político. São Paulo: Editora UNESP. 